Substituting for Families? Schools and Social Reproduction in AIDS-affected Lesotho

Dr Nicola Ansell

Centre for Human Geography

Brunel University

Kingston Lane

Uxbridge

UB8 3PH

01895266085

Nicola.ansell@brunel.ac.uk 


\section{Substituting for Families? Schools and Social Reproduction in AIDS-affected Lesotho}

Families, the state and employers all have a broad if differentiated interest in securing the daily and generational reproduction of society. Whereas in Western countries, the past two decades have witnessed a progressive displacement of responsibility for social reproduction from the state to families, in southern Africa, day-to-day social reproduction has always remained overwhelmingly the preserve of families. Today, however, the AIDS pandemic is radically transforming family life for many children, and prompting concerns (arguably a moral panic) about the potential breakdown of social reproduction. Even in Africa, schools have long supplemented families in delivering generational reproduction, albeit geared around the transfer of "factual" knowledge and with a narrow focus on preparing new generations of workers. In light of the AIDS pandemic, a number of commentators have suggested ways in which schools could further substitute for the diminishing capacities of families. Based on interviews with decision-makers and analysis of policy documents, I explore a number of interventions being enacted in Lesotho's schools. I argue that such initiatives remain small in scale and often justified in relation to retaining children in school. In practice both government and employers remain more interested in the generational reproduction of workers than in daily reproduction. If the welfare needs of AIDS-affected children are to be met through schooling, there is a need for the education sector's role to be understood in relation to an ethics of care, rather than the functionalist production of a future workforce.

Key words: social reproduction; AIDS; schools; education; Africa

\section{Introduction}

In southern Africa, AIDS is posing a dramatic challenge to the capacity of families to care for children, thereby fulfilling the social reproduction role that is generally expected of them. While in other parts of the world, influenced by neoliberalism, responsibility for social reproduction is increasingly displaced onto families, in Lesotho and other southern African countries families are severely strained by sickness and death among their adult members. The one aspect of social reproduction in which most governments worldwide have retained a proprietorial interest is the generational reproduction delivered through schooling (although even here, in many countries, families are increasingly expected to cover the costs). This paper explores the extent to which responsibility for social reproduction is being redistributed in AIDS-affected Lesotho, and in particular the roles being adopted by the school sector. 


\section{Geographies of Social Reproduction}

Geographers have given considerable attention to aspects of social reproduction, particularly over the past two decades, including the changing locus of responsibility. However, social reproduction is a broad concept and has been approached in diverse ways. Geographers have defined social reproduction as: "The interdependent reproduction both of the social relations within which, and the material and discursive means through which, social life is premised, sustained and transformed over time" (Lee 2000:760) or: "material and social practices through which people reproduce themselves on a daily and generational basis" (Katz 200I:7II). These definitions highlight the diversity of processes involved, both material and discursive/social, and the fact that these processes are not simply geared to reproducing societies unchanged, but contribute to both continuity and change. Given this dynamic role in society, the temporal dimension of social reproduction has received surprisingly little attention. Social reproduction is fundamentally about ongoingness over time, and while it concerns people's daily health and welfare, it simultaneously incorporates the long term reproduction of a labour force (Aitken et al 2006).

There are clear distinctions in the focus of interest in social reproduction among scholars from different intellectual traditions. Of relevance to the research presented here is a divergence of interest between feminist scholars who are principally interested in the daily work of reproduction, and in particular the ways in which this is gendered, and those concerned with education who are more interested in processes of generational change and continuity.

These distinctions are apparent within geographical research. Most geographers writing on social reproduction have done so from a feminist perspective, and focused on women. Their emphasis is on the processes shaping responsibility for social reproduction, rather than reproductive processes themselves. Recent research, for instance, has highlighted how the work of social reproduction, considered "outside" of production and unwaged or very poorly paid, has been largely undertaken by women and, in Western societies, disproportionately by immigrant women (Mattingly 200I; Mitchell et al 2003). A related focus has been the effects of women's workforce participation, and the difficulties of balancing paid work with roles in social reproduction in, for instance, the UK (Perrons 2000; Ward et al 2007), and Russia (Pavlovskaya 2004), and the way in which increased levels of maternal employment are facilitated through state regulation of childcare (Mahon 2006). Equally, research has examined how, under neoliberal regimes, state funding for welfare has declined, shifting the burden onto women, and particularly the least wealthy (Haylett 2003). Feminist geographers have also critiqued the very notion that there is a distinction between 
productive and reproductive work, emphasising that reproductive work also produces value (Mitchell et al 2003).

While feminist geographers are principally concerned with the effects of changing regimes of social reproduction on women, the emphasis of research within children's geographies has unsurprisingly highlighted the effects on children. As Katz (1991:488) points out, "A key practice of social reproduction is the socialization and education of children". Here, the focus is more on generational change, and on processes and outcomes rather than distribution of workload. Young people are recipients of investment in social reproduction, and concern lies with whether their needs are met, and also how processes centred on children more widely contribute to continuity and change in society.

Through a range of processes focused on children, societies are reproduced. As well as children's day-to-day physical sustenance, social reproduction involves their acquisition and assimilation of the shared knowledge, values and practices of social groups (Katz 2004). One of the key means of achieving this is through education. As will be explored further below, schooling, particularly in the West, is geared to constituting individual(ised) subjects oriented to success in the global economy (Mitchell 2003). Geographical studies have also implicated schooling in the wider reproduction of class relations, at a variety of spatial scales, including internationally (Waters 2002; Waters 2006a; Waters 2006b). Across the globe, different "strategies of the social reproduction of youth and children, their education and training and their acculturation carry within them imagined paths to global competitiveness (both in the "race to the top" and the "race to the bottom")" (Ruddick 2003:257). Far from achieving increased global uniformity, an increasingly differentiated labour force is being produced (Katz 200I). This differentiation is fuelled in part by the differing levels of commitment and resources that states and capital apply to meeting children's current and future needs across the globe.

Beyond the items cited above, there has been remarkably little written by children's geographers about social reproduction. Although one of the earliest papers to highlight the potential significance of children within the discipline did so from the perspective of social reproduction (Bunge 1977), the recent concern of children's geographers to focus on children as social actors living in the present, rather than bearers of needs, oriented toward the future (the idea that children are "human beings" rather than "human becomings" (James et al 1998)) has probably been a deterrent to work in this area. Yet young people may certainly be seen as actors in social reproduction. Children work on the production of their own futures through, for instance, work 
in school and training (Qvortrup et al 1994). They also play important roles in securing social reproduction more widely, through domestic and caring work. Impoverished households, especially in Africa, often depend on the efforts of children (Jennings et al 2006; Robson 2000; Robson 2004a; Robson 2004b; Robson and Ansell 2000; Robson et al 2006). In bringing together these two threads, the paper responds to Ruddick's (2007:628) recent call for increased dialogue between "feminist geographers working on women's issues and geographers addressing children's issues".

\section{Securing Social Reproduction: Actors and Interests}

This paper focuses on the changing roles played by different actors in securing social reproduction in light of the AIDS pandemic in southern Africa. In all societies, social reproduction is delivered by a range of actors. While much of the work of social reproduction is undertaken in the private sphere of the family, the state and private capital also play varying but generally significant roles. All have an interest in ensuring social reproduction happens and fulfils certain goals.

All societies require some form of social reproduction to survive. For the continued functioning of a capitalist economy, new generations must be raised and imbued with both physical health and fitness and particular sets of knowledges, skills and dispositions. Firms are major beneficiaries, but in pursuit of profit seek to displace the costs of social reproduction onto either the state, or, at lesser cost in taxation, onto families, and in particular the unpaid labour of women. Furthermore, as Western states are increasingly interested in promoting capitalist production rather than social reproduction (Smith 2002), they too shift responsibility onto families. Capitalism relies on families to deliver not just generational but daily reproduction: "Social reproduction ... depends upon the household or family system and the more general areas of private activity, not least consumption and other activities of the working class that induce and enable it to present itself for work on a daily basis" (Fine and Saad-Filho 2004:7I-72).

Since the late twentieth century, in countries worldwide, the influence of neoliberalism has thrown the costs of reproduction increasingly onto the households and communities of the poor, with diminishing wages and insecure contracts (Bezuidenhout and Fakier 2006). In Western countries insecurity is exacerbated by diminishing support from once-Keynesian welfare states, placing responsibility for children's welfare ever more firmly with families (Ruddick 2007). This displacement from public to private sphere is matched by a broader spatial shift in responsibility. Economic globalisation assists firms in further avoiding these costs. "The important point about 
globalization from the standpoint of children's geographies is that there is no longer a need for capital investments to be secured at particular locations" (Aitken 200 I:I23). In what Katz describes as "vagabond capitalism", firms move around the globe seeking out sources of cheaper labour rather than investing in the future workforce in a fixed place.

In southern Africa, the spatial separation of social reproduction from production predates the current neoliberal era. From the nineteenth century, the region's colonial and postcolonial economies depended on labour migration. Until very recently, almost all Basotho' men worked for some years as miners in South Africa, but the supply of mine labour was raised, mainly by women, in rural areas, where care of the sick and elderly also took place (Bujra 2004; Murray 198I). Prohibited from migrating to South Africa (Epprecht 2000), Basotho women also engaged in subsistence agriculture, relieving employers of the need to pay a "social wage" that would cover the cost of reproduction by supporting an entire family. This spatially-stretched mode of capitalist production has supported the development of complex, fluid kinship relations and family forms.

Today, the mining industry is declining as a source of employment (from 125,000 to 60,000 since 1990 (Kingdom of Lesotho 2004)), with the work increasingly confined to a small number of specialist life-long miners. In its place a garment industry is emerging on the fringe of Lesotho's towns and cities. Garment factories employ a largely female workforce that now outnumbers the mineworkers. While mining was geographically fixed and had some interest in the reproduction of labour, even if this took place at a distance," the garment sector is the classic example of "vagabond capitalism”: extremely mobile with minimal interest in local labourforce reproduction.

However, it should be pointed out that capital has not entirely withdrawn from concern with social reproduction. As Haylett (2003:768) highlights, "The language of social stability and social inclusion is on the agenda of global economic institutions". Even organisations like the World Bank support social policies that fit their agendas such as promoting investment in "human capital" (Haylett 2003).

One area of social reproduction in which states continue to invest and take an active interest is education, although commercial interests and private sector providers are increasingly involved. Across Africa, there was widespread disinvestment from education in the 1980s under structural adjustment programmes that in some cases brought falling enrolment. However, since the 1990s many countries have substantially increased access to education, in part driven by the Millennium Development Goals that set a target of universal primary school attendance by 2015 (United 
Nations 2007). Funding for universal primary education is provided by a number of donors, including notably the World Bank.

Education serves the needs of the capitalist economy by providing labour with necessary skills and dispositions. The economy requires the reproduction, not only of fit and healthy adults, and the skills necessary for production, but also of the relations of production (Althusser 1972).

Hierarchies of social class and occupation are reproduced "as each new generation takes up social roles and occupations left by the previous generation as well as newly emerging occupations" (Demaine 2003:I26). According to Althusser (1972), education operates as an "Ideological State Apparatus" instilling in students the dominant ideology, causing them to accept their prescribed roles in the economy.

The processes through which schools reproduce existing social relations are manifold. Hierarchical structures and authority patterns within schools, including the rewarding of particular behaviours through grades and certificates, prepare students for workplaces (Bowles and Gintis 1976). Through what Freire (1972) terms "banking education”, students are encouraged to operate as meek receptacles, receiving, filing and storing transferred knowledge. In Third World countries, this assists in "cultural invasion" (Mayo 1995) because the version of knowledge imparted is that which supports the dominant (generally Western) ideology and contributes to students' internalisation of their oppression. Students are immersed in a "culture of silence" in which they are encouraged neither to question, nor to be creative.

There is a danger that these accounts suggest an over-mechanistic view of how education operates: schools in practice not only transfer ideology between generations, but actually produce new knowledge (Apple 1982). In Apple's view, students themselves have power and play important roles in social reproduction, although often in contradictory ways that ultimately do not enable them to challenge power structures in wider society.

Bourdieu and Passeron (1977) elucidate students' active engagement in social reproduction in their explanation of French universities' role in reproducing relations between social groups. They assert that the language used in educational institutions is not intended to communicate knowledge. Students themselves are complicit in the myth that they understand: a myth which casts failure to understand as an inadequacy of students, not the system. Students from the lower classes understand least, due to their lesser familiarity with academic language. Thus the university 
affirms and legitimates the dominant class' relation to culture. Schools in these varied ways not only reproduce inequalities, but also help to depoliticise class relations by legitimating inequality.

In practical terms, then, social reproduction is undertaken both by families and schools. In both cases it tends to be functional to capitalism. Neoliberal governments, keen to promote capital investment and economic growth, seek to reproduce society amenable to that outcome, but with costs borne by families where possible. Families and schools play distinct roles in relation to social reproduction, with somewhat different aspirations. While neither families nor schools are easily defined, homogeneous or bounded institutions, it is possible to identify some broad functions that each performs. At home, families are concerned with both day-to-day needs and generational reproduction. In general they aim to provide prepared food, well-maintained shelter, hygienic surroundings, clean clothing and opportunities for rest and recuperation; to offer psychosocial support to all members and physical and emotional care for infants, the sick and the elderly in particular; and to promote the acquisition of certain skills, knowledge, behaviours, values and expectations. Schools, by contrast, have a narrower purpose and are principally concerned with generational reproduction. Commonly, education systems view children as "human becomings" that they are explicitly preparing for work. They generally aim to provide a safe environment for learning, where children acquire skills, knowledge, behaviours, values and expectations, mainly aligned to labour market needs.

It is important to recognise that social reproduction is not simply instrumental to capitalism. Some form of social reproduction is necessary for the sustenance of any society, whether capitalist or not, and is essential for the welfare of individuals and families. Furthermore, the work of social reproduction is not generally coerced: there are psychological and emotional motivations, including feelings of individual productivity and personal value that result from providing care, as well as the formation of individual and group subjectivities (Mitchell et al 2003). "[U]npaid family and community work involving the work of care for dependent others, is ... productive of meanings and relations of an intimate and psychological kind, which are not reducible to the imperatives of capitalist social organisation" (Haylett 2003:769).

The work of social reproduction is also often motivated by a sense of responsibility. Emotions and moral commitment come together in an ethics of care that justifies, for instance, British parents' sense of moral commitment to caring for their children personally or through family-based provision, irrespective of the demands of economic rationality (McDowell 2005). These understandings of caring responsibilities are gendered in complex ways (McDowell et al 2005). 
Ethics and responsibility are not confined to the family context. Nor are the family, capital and the state the only institutions involved in securing social reproduction. Media, mass culture and religious institutions are significant (Katz 2004) and, in Africa and elsewhere, an increasingly prominent role is played by non-governmental organisations. Although not unambiguously outside the market, these various bodies do not simply focus on the supply of future workers and consumers for a market economy, but may be motivated by varied notions of responsibility (Bosco 2007). Lesotho's education system was first established by Christian missionaries, eager to "civilise" the population. Their focus on behaviour and hygiene was not motivated simply by a wish to train a workforce, and some educated in mission schools led struggles against capitalist exploitation. Vestiges of this wider role in social reproduction, beyond the service of capitalism, persist in schools today, most of which are still owned and governed by the country's churches. There is both precedent and opportunity for schools to serve an expanded role in social reproduction, beyond what is conventionally labelled "education". In light of the impacts of AIDS highlighted in the next section, this potential role merits attention.

\section{A Breakdown of Social Reproduction? The Impacts of Aids in Southern Africa}

Although social reproduction comprises dynamic processes that can invoke social change, societies tend to be reproduced in relatively stable forms, with modest government influence aimed at (re)shaping society along certain lines. However, social reproduction is said to break down where social transformation is attempted through violence, or where there are dramatic changes in social practices. Social reproduction relies on social relations that are accepted and do not need to be enforced; dramatic events that render usual conventions impossible, such as occur in situations of famine, can lead to breakdown. Rapid social changes can also cause generational social reproduction to fail if the connection between production and social reproduction is dissolved, where, for instance, there is a disjuncture between what children currently learn at home, and the skills they will in practice require in future work as adults (Katz 199I).

One dramatic change that "constitutes a stunning blow to processes of social reproduction, particularly of labour power" (Bujra 2004:637) is Africa's AIDS pandemic. This is profoundly affecting the functioning of the migrant labour system in southern Africa, and its capacity to deliver social reproduction. 
"Now this transmission belt of new labour for old is fraying as the hidden virus is spread to rural wives or sexual partners, incapacitating those who labour on the fields and in houses and turning the next generation of migrants into orphans and street children cast adrift even from the insurance policy of rural subsistence" (Bujra 2004:632)

AIDS interferes with conventional modes through which societies are reproduced, with impacts on children's welfare in terms of both generational and immediate day-to-day reproduction. In AIDS-affected families there is a diminution of capacity to undertake social reproduction. Adults become sick or die and their contribution is lost. Other adults, in order to compensate for loss of household productive capacity, focus on productive rather than reproductive work. Children may, as a consequence, be raised by grandparents, other relatives, non-relatives, or in child-headed households (Barnett and Whiteside 2002; Desmond et al 2000). Children are deprived of some of the arrangements that would otherwise be in place for their welfare, in terms of physical sustenance, psychosocial support and intergenerational transfer of knowledge (Loevinsohn and Gillespie 2003; Munthali and Ali 2000). In such circumstances, children may themselves have to make a greater contribution to social reproduction in such roles as caring for the sick and substituting for adults in domestic work (Ansell and van Blerk 2004). Finally, many children are withdrawn from school, either to allow them to fulfil other roles, or because there is insufficient money to pay their fees (Bourdillon 1999; Danziger 1994). Thus families may no longer be able to fulfil those common aspirations of families outlined above: the provision of prepared food, wellmaintained shelter, hygienic surroundings, clean clothing, rest; the physical and emotional care for infants, the sick and the elderly; and there may be reduced opportunities to acquire expected skills, knowledge, behaviours, values and expectations.

\section{The Research: Methods and Context}

Within this context, I undertook research to explore how Lesotho's education sector is responding to the AIDS pandemic, focusing specifically on whether and to what extent it is taking on some of the roles that many families can no longer adequately accomplish. Schools are Lesotho's most widespread public institutions: most children spend many hours in school every week, and a large proportion of public spending is channelled into them. In the absence of well developed social welfare systems, any large-scale transfer of responsibility for social reproduction from private to public spheres might most effectively be achieved through schools. I was therefore interested in whether those involved in education see schools as having a role in responding to a perceived breakdown in social reproduction; whether schools are being expected to take on roles 
that otherwise fall to households and families; whether the education system is responding to the needs of children who are taking on more reproductive work themselves; and whether interventions adopted reflect particular interests. To explore these questions, I interviewed 44 decision-makers from government, donor agencies and NGOs ${ }^{\text {iii; }}$; analysed national and international policy documents; examined agency reports and recommendations; explored curricula and curriculum materials; and conducted interviews with school heads and teachers at four diverse schools.

Lesotho has the third highest HIV prevalence worldwide, with $23.2 \%$ of I5-49 year olds infected (UNAIDS 2006) and 19\% of 0-17 year olds orphaned (UNAIDS/UNICEF/USAID 2004). Compared with many African countries, Lesotho's epidemic is relatively recent, with a sharp increase in prevalence estimates from 3.1\% in 1994 (World Bank 1997) to 28.9\% in 200 I (UNAIDS 2004). Primary school enrolment has risen considerably since the introduction of a World Bank-funded Free Primary Education programme in the late 1990s, and gross primary enrolment has reached $128 \%$, with $85 \%$ of the school age population registered for school (Ministry of Education and Training 2004). ${ }^{\text {iv }}$ Approximately $70 \%$ of primary school leavers progress to secondary school, but a much smaller proportion complete the full 12 year school cycle (Ministry of Education and Training 2004). In contrast to many African countries, considerably more girls attend school than boys.

There are a number of factors that contribute to the character of education in Lesotho. The schooling system was inherited from Britain, as the former colonial power, and even today English examination boards regulate the public examinations sat by students completing high school. The entire school system is ultimately focused on maximising the number of students passing these examinations, with annual tests of acquired knowledge used to filter progression of students to the next class. Teaching tends to be very didactic, dedicated to the passing on of factual knowledge. Furthermore, the content of education is principally academic. Few practical subjects are taught, largely due to the additional costs involved, although most schools teach agriculture, and the Development Studies curriculum involves a practical project at secondary level. Schooling is geared towards providing the most able students with certificates that will help them find work; not preparing them for reproductive work in the private sphere (Ansell 2002b).

All this sits uneasily with the declared objectives of education in Lesotho that were established through a National Dialogue that solicited the views of the entire population through community 
meetings in 1977/8. According to the report from that exercise, cited in almost every policy statement subsequently issued by the Ministry of Education, education should:

"Help children to an understanding and acceptance of the highest standards of social living needed in present day Lesotho society" and "Develop one's character in selfunderstanding, understanding and acceptance of others, co-operation and services; personal integrity and responsibility and the love of God reflected in one's relationship with others and in one's behaviour and moral standards. This should be seen within the context of the understanding and appreciation of healthy ways of living and good habits" (Policy Guidelines 198I)

This perspective clearly presents a more holistic role for schooling within social reproduction than preparing future economic actors.

Significantly, education in Lesotho is not simply an arm of the state. Unlike Western education systems that are largely controlled by government (national or local) and responsive to voters and capital (that provide the finance), most innovations in Lesotho's education system involve agencies other than the Ministry of Education and Training, and are funded by bilateral or multilateral donors, albeit indirectly through budgetary support. Many actors shape responses to AIDS that are channelled through the education system. These include branches of government: the ministries of health and finance are influential, and the Office of the First Lady sponsors bursaries for orphans and vulnerable children. Other government agencies are also involved, including the Lesotho AIDS Programme Coordinating Authority (now replaced by a more independent National AIDS Commission), the National Curriculum Development Centre and the Examinations Council of Lesotho, as well as Lesotho College of Education (the country's teacher training institution). Donors provide considerable funding for new initiatives in the education sector: the World Bank's funding of the universal primary education programme was contingent on changes in curriculum and teaching; Development Cooperation Ireland (now Irish Aid) is involved in developing measures to address the impacts of AIDS in schools. A number of United Nations agencies fund or run AIDS-related programmes through schools, notably UNICEF, UNDP, UNAIDS, WFP and UNFPA. Funding for AIDS-related programmes also comes from the Global Fund and a sizable part of this is channelled through the Ministry of Education. There are international and local NonGovernmental Organisations, including youth organisations, involved in various ways, either through formal agreements with the Ministry of Education, or more informal arrangements with schools. Almost all of Lesotho's schools are owned by churches: although the Ministry pays the 
salaries of most teachers, and curricula and examinations are set by government bodies, the churches own the buildings and appoint all teachers and headteachers, and have considerable influence on the governance of schools. Teaching unions, too, are involved in diverse ways, including running programmes for teachers and students. And inevitably, what happens in schools reflects the actions of school principals, school committees (comprised of representatives of local churches and community members), teachers and students. All of these have particular interests that they pursue, many of which relate to the character of the societies they wish to see (re)produced through the school system.

The various actors involved in shaping education in Lesotho are responding to a range of different prompts. These involve perceptions of need identified within the nation's schools, but they are shaped to varying degrees by a wider international policy context and discursive framing of the epidemic and its consequences. Donors, in particular, have considerable influence, and are deeply imbricated in an evolving international consensus on appropriate policy responses.

\section{Extending the Roles of Lesotho's Schools}

Until very recently education systems in Africa responded to the AIDS pandemic almost exclusively through a focus on AIDS prevention and (to a lesser extent) addressing stigma. By 200I, however, Peter Piot (200I:I I), Executive Director of UNAIDS was arguing that:

"The education sector must expand its role beyond teaching to become a community resource for advocacy on the sensitive issues surrounding HIVIAIDS ... It should also help in providing community infrastructure to support welfare services and protect those most marginalized, such as orphans"

Although such statements are far from common in official reports, the findings of the UNAIDS Inter-Agency Task Team on Education (IATT) Global HIVIAIDS Readiness Survey would suggest that this expanded role for schools is increasingly accepted:

"In societies where HIVIAIDS has an impact, individuals, communities and institutional staff may be dealing with multiple incidences, collapse of conventional support systems and the stress of being affected or even infected. In these circumstances, children in particular may fall through the net and not receive the traditional support that families and communities have to offer ... Care and support in the educational setting involves establishing 
mechanisms to address the psychosocial, physical, emotional, educational and spiritual needs of affected and infected individuals ... 75\% of the 20 countries responding indicated that teachers have received training in caring for affected and infected learners" (IATT 2004:127)

It is noteworthy that the needs identified here extend well beyond those that are generally considered to be within the remit of education systems. It appears that schools are assumed to be appropriate institutions to take on wider elements of social reproduction. "Care and support" appears in many countries' education sector policies and guidelines on AIDS:

"HIVIAIDS Care and Support are defined as interventions or sets of interventions whose purpose is to mitigate the impact of the HIVIAIDS epidemic on individuals, families, communities and national care and support activities ...

- CARE: involves services to stabilize and/or improve the mental, physical health of individuals infected and affected by HIVIAIDS

- SUPPORT: involves interventions to stabilize and or improve community and societal systems affected by the epidemic care continuum ..." (Republic of Zambia 2003:27)

"Early childhood care and education should reach out to young OVC [orphans and vulnerable children] and those with special needs in the community and make special efforts to compensate for any lack of care and support they may experience in their home environment” (Republic of Kenya 2004:22)

These statements, however, are confined to sections of policy statements that dwell much more on prevention, and also issues of discrimination. The Zambian policy document, for instance, devotes just over one page out of 38 to "care and support". Similarly, "community responses, care and support" is the final substantive chapter of the report for a workshop on education sector responses to AIDS organised by the Commonwealth Secretariat (Rispel et al 2006). This constitutes 3 pages of the 96 page report. Furthermore, the IATT report suggests that relatively little attention has actually been paid to these needs:

"Ministries of Education recognise that care and support for those infected and affected is a severely neglected issue" (IATT 2004:125) 
"When asked whether financial resources for issues other than awareness, prevention, behaviour change or curriculum development have been allocated to address the impact of the HIVIAIDS epidemic, only ... 43\%, answered Yes" (IATT 2004:53)

Among the six priority areas for responding to AIDS identified by Bennell et al (2002:xi) are "school feeding, pastoral care and counselling, financial assistance with fees and school-related expenses", yet little support is made available for children affected by AIDS in any of these areas. This may be partly due to a sense that children's psychosocial and material needs are the responsibility of other government departments such as Social Welfare (IATT 2006), but these other departments have very much smaller budgets and reach.

Within Lesotho, the Ministry of Education is regarded as particularly pro-active in relation to AIDS. It was one of the first two ministries to formulate a strategic plan setting out how it would address AIDS and the first to conduct an impact assessment. This examined impacts on pupils as well as teachers, administrators and parents. The Ministry recognises a need "to initiate long-term interventions for special needs focus groups including children with HIVIAIDS, AIDS orphans ..." (SADC 2002:37), and declares that "The intention of the MOET is to aggressively address the impact of the HIV and AIDS pandemic on the education sector in general, and in particular on school-going age children" (Ministry of Education and Training 2004:10). It has expressed an intention to "Explore combining educational provision with care and welfare of orphaned children" (Lehohla 2002:10).

Among many of those involved in shaping education there is a strong sense that schools should be taking on some of the roles normally expected of families:

“it's not very different from what we have been doing in our culture, but you know, we used to have, you know, structures independently who would give advice to young people, but then because of some changes the structures are no longer there, therefore education has to play some role there, and now it has to be done by teachers" (Curriculum Advisor, NCDC)

"I think we need to give them life skills that even when they become orphans when they finally lose parents they are able to go on in life because you look at the family structure, the extended family structure, it's collapsed ... Do we still allow schools to remain what they were or are we going to change our schools so that they facilitate for both the 
vulnerable and the not vulnerable, because, the orphans, who teaches them, em for example I teach my daughter, wash your clothes, do what, do what. Who does that with the orphans? What do we do to the school, to the education system so that it accommodates both the vulnerable and the non-vulnerable, that the teacher does not only talk about Christopher Columbus, does not only talk about the first world war, but also talks about basic hygiene for the benefit of this one who will not have anybody talking about that at home. Basic agricultural skills for this one who will not have anyone giving such instruction at home. Do we let schools remain what, our primary schools remain what they have always been or are we going to do something to make them change so that these orphans and other vulnerable children are covered and equipped with life skills?" (Inspector, Primary Services, Ministry of Education)

These quotations suggest that personnel are concerned that schools should substitute for families by giving advice, and by imparting skills and knowledge that go beyond what would normally be undertaken by schools. Schools would contribute to both day-to-day reproduction (the giving of advice) and the wider aspects of generational reproduction, beyond preparation for the workplace, that have hitherto been largely the preserve of families.

At policy level, responses to AIDS have been conceived of principally in relation to a demand for new skills and knowledge. By far the greatest emphasis is on curriculum change, and specifically life skills education. Life skills are a curricular area that has been promoted across southern Africa by international donors and UN agencies, and there are a number of innovative programmes operating in Lesotho, initiated and funded by several different organisations. While the concept is understood in varied ways (Boler and Aggleton 2005), the quotation above represents a rather idiosyncratic perspective; life skills are generally seen more in terms of thinking skills and training in assertiveness, and are principally focused on AIDS prevention, even though in theory teaching in this area should produce more broadly resourceful individuals. According to the Health and PE Curriculum Advisor at Lesotho's National Curriculum Development Centre, they are also used to tackle the stigmatisation of AIDS. They do not, however, provide the practical skills that most children acquire at home, and cannot be seen as substituting directly for families in social reproduction.

Another curricular innovation that seeks to respond to AIDS is Population and Family Life Education (POP/FLE) which is promoted by UNFPA. This is implemented in some schools, although there is resistance from some bodies, notably the Lesotho College of Education, which 
makes it unlikely that the programme will be taught as intended at a national scale. POP/FLE focuses on sexual reproductive health, health and nutrition, family life, substance abuse and gender equality and empowerment as well as more general population-related knowledge and understanding. As such, one might anticipate that it could contribute to students' acquisition of knowledges relating to social reproduction.

There are a range of more material measures through which schools are supporting social reproduction in the face of AIDS. Bursary schemes are used to support the households of orphans and vulnerable children, enabling children to attend school who otherwise might not be able to, including at secondary level. The free primary education programme has greatly reduced the cost of sending children to school: not only are there no fees, but children are provided with books and pencils. However, according to one of the primary school teachers interviewed, some children stay home because they have no uniform, which remains costly for families. Some schools hold second hand uniform sales, which reduce this expense. School feeding programmes are also intended to support vulnerable children, and some are supplied with food packages for school holidays. Vegetable gardens are a means of both providing children with nutritious food that is not adequately supplied at home, and also developing knowledge and skills associated with growing food on a domestic scale. Human Rights Watch has suggested that keeping schools open at night would offer a valuable resource for AIDS-affected children that lack a secure home environment (Human Rights Watch 2005), but this has not been taken up in Lesotho.

Beyond extending schools' roles to improve children's physical welfare, innovations have been introduced to support their emotional welfare. These include life skills training, plans to train one third of the teaching force in counselling and "to train teachers in psycho-social care and support techniques such as play therapy" (Ministry of Education and Training 2004: I I).

Moreover, there is a widespread recognition that children themselves are engaged in the work of social reproduction in their own homes. Children assist their families in a range of ways, particularly if adult household members are sick and unable to undertake tasks for themselves; if caregivers have died; or if there are sick people who need care. There is a perceived need for children to be provided with knowledge and skills to undertake such work: skills and knowledge that can be implemented today, rather than generational transfer of knowledge in preparation for a distant future. 
"So it would be important for every, you know, primary child, to know the basic knowledge about HIVIAIDS. And especially about the care, care and support, because we are now facing a problem where ... these children are unfortunately taking care of those people out there ... One would really be happy to see them given that knowledge about care and support, because they are now doing it, they are now caring and it's not very easy for them" (Curriculum Advisor, NCDC)

Schools in Lesotho are adopting on a range of practices that extend the traditional functions of education. No longer do schools focus only on academic work or on the generational reproduction of a productive labourforce. There is a recognition that for many children attending school, future employability is not necessarily the top priority. However, these initiatives often remain either small in scale or confined to relatively few schools.

\section{Motivations: Keeping Children in School}

There is a broader framework in which these changes are taking place. It is highly significant that arguments for schools offering care and support for children affected by AIDS are very often couched in terms of enabling them to attend and succeed in school. Bursary schemes, for instance, enable AIDS-affected children to attend school; feeding schemes are often advocated as a way of encouraging children to attend or return to school. The Scholarships Officer at the MOET justified the use of school feeding in this way:

"this kind of children have problems, because really if you give a needy child a scholarship and he has to go to school on an empty stomach, he would definitely choose to look for a job and leave school"

Even psychosocial counselling is used as a means of meeting the needs of children as students, assisting them to continue with their schoolwork. The overall emphasis is mostly on traditional educational needs, with social needs only addressed where these are seen to contribute to meeting educational needs. The plan to introduce POP/FLE, for instance, was justified in relation to the risks AIDS poses to education, more than the direct threat to social reproduction:

"We are ... aware that the traditionally extended family structure which provides a safety catch for orphans, cannot be expected to cope with the anticipated increase in number of AIDS orphans. We need to seriously address the change of attitude and sexual behaviour, 
because issues of the infected and the affected people impact negatively on teaching and learning process” (Government of Lesotho/UNFPA 2003:iv-v)

This tendency is apparent internationally. Many reports advocate care and support, but with the ultimate motivation being to return children to school or keep them in school. The Commonwealth Secretariat report is concerned with educational outcomes, even when addressing "community responses, care and support" (Rispel et al 2006). The Human Rights Watch (2005) report, similarly, addresses many of the ways in which AIDS is impacting on social reproduction in the private sphere - but only in relation to its impacts on children's school education.

"Schools should be enabled to learn how to play an active role in looking for HIV affected and infected children in their communities and in persuading them (or their parents/guardians to allow them) to come back or remain in school” (UNESCO 2004:3)

Keeping children in school, of course, need not fulfil educational objectives alone: without securing children's attendance it is not possible for schools to meet any of their reproductive needs:

"One obvious option is to concentrate on getting these children into school and keeping them there as long as possible. In this way, some measure of social protection and monitoring can be provided, together with access to nutrition, the cognitive skills required for informed decision-making, and sufficient education for employment or entrepreneurial activity” (IATT 2006:47)

It is not this wider concern with children's welfare that permeates most policy documents. In Lesotho the term "mitigation" is widely used in relation to policy responses to those who are indirectly affected by AIDS, but there is no real consensus as to what this is referring to within the educational context: whether it is about using the school system to mitigate the wider impacts of AIDS on society, or about mitigating the effects of AIDS on children's attendance and learning.

\section{Concluding Discussion}

Schools are seen as an appropriate mechanism for providing children with knowledge and skills to avoid infection with HIV (thereby contributing in one way to social reproduction). They are also (though less widely) seen as needing to respond to a changing situation and to pursue alternative 
strategies, including feeding programmes and counselling, in order to continue educating children. The emphasis, however, is mostly on meeting traditional educational needs. Although there is also is a wider concern with supporting AIDS-affected children - meeting their welfare needs - it is less frequently expressed and there is no apparent coherent strategy or overview. Lesotho's education system continues to play a role in generational reproduction and especially the remaking of a labourforce, but does not see itself as substantially contributing to day-to-day reproduction. This scenario raises the question of why, given the high level of awareness of need, schools are not being seen and used more widely as a way of substituting for families in social reproduction.

In part, the explanation may lie in resistance to change within organisations, including Lesotho's education ministry. The failure to convert accepted wisdom to policy and practice in Lesotho's schools has been reported elsewhere (Ansell 2002b). However, inertia due to preoccupation with the conventional aims of education (emphasis on examinations, and less directly employment) does not offer an adequate explanation given that many changes do occur in Lesotho's schools, including in response to the AIDS pandemic. It seems that there is relatively little pressure on the Ministry of Education from other branches of government, or from donors or UN agencies, to undertake the work of social reproduction other than with the aim of retaining children in school.

High levels of school attendance (and to some extent achievement) are in the interests of a wide range of actors. Pursuit of this goal is motivated by, for instance, the Government of Lesotho's perceived need to attract inward investment in order to secure future economic growth; by the UN Millennium Development Goals and other international targets; and by the World Bank's belief in investing in human capital. While the form of education delivered in Lesotho may not (intend to) produce the type of neoliberal subjects that are the rationale for many educational innovations in Western countries (Mitchell 2003), schooling does play a part in the reproduction and transformation of social and material relations, if seldom to the advantage of the country's poor (Ansell 2002a). It is much less easy to identify, from among the actors that have influence in shaping Lesotho's education system, those that might benefit from investment in wider aspects of social reproduction. If schools do not deliver for children the physical sustenance, emotional support and domestically relevant knowledge, values and practices that are increasingly unavailable in many children's homes, children themselves will suffer but the broader impacts are less clearcut.

Most employers have a general interest in the social reproduction of labour - in Western societies they seek to maximise the pool of potential workers to draw on, and are supportive of policies 
that free parents for employment, as well as benefiting from new recruits who are not only literate and disciplined, but also physically and mentally healthy. In Lesotho, however, the major employers - the mines and garment factories - have less to gain from an extension of state involvement in social reproduction. The mining industry is able to draw on a large pool of underemployed men, and every morning lengthy queues of women gather outside garment factories hoping for work. With adequate labour available to meet their needs for the foreseeable future, these employers will not be greatly concerned about generational reproduction, and their demand for the state to play a role in securing daily reproduction is likely to be lower still. The presence of a child, particularly an orphan, within a family is seldom a barrier to workforce participation among those who are poor and in need of income. Indeed, the need to support children is more likely to be an incentive to find work, albeit at some cost to children's day-to-day welfare. There are many other matters that more severely impede immediate access to labour, such as the availability of antiretroviral therapies, on which employers are much more likely to lobby government.

The Lesotho government is doubtless concerned to be able to compete in a future global market to attract employers, and needs to present to potential investors evidence of a reasonably welleducated workforce. In contrast to Western and post-Socialist countries, however, Lesotho has no history of significant state intervention in day-to-day reproduction. Children's welfare needs have been secured through a spatialised, gendered division of labour. Both the state and capital have been able to assume that social reproduction would be taken care of.

It is children, then, who are the most affected by the incapacity of families to secure their wellbeing, but children cannot make direct claims on the state. As Qvortrup (2005:10) opines, "children are arguably the last remaining group which has not yet been recognized as having a claim on current political and societal resources"; "nowhere have children a constitutionally-based right to receive welfare support from the state ... Even in welfare states, children are basically dependent on their parents" (Qvortrup 2005:10). Without parents, they have little prospect of securing their welfare needs through provoking a change in what schooling delivers.

To the extent that Lesotho's education system does accommodate the welfare needs of AIDSaffected children it does so for reasons that relate more to responsibility than to economics. In the absence of a strong economic rationale, or capacity on the part of children to make their own claims on the state, their welfare must depend on ethical motivations. In many organisations, not least "development"-oriented non-governmental organisations, responsibility is a pervasive 
motivating force. Within schools, individual teachers are certainly driven by their own emotional responses, as Sister Maria-Anna relates:

\begin{abstract}
"The thing that the teachers are doing is to teach in class about HIVIAIDS and to accept those whose parents have passed away, to make them feel there's someone who cares. Some teachers pay the costs for students who don't have parents. They also comfort them by buying sweets and Simbas (fried potato snacks) that they give to the class - not just to those pupils to embarrass them, but in their hearts it's for those whose parents have passed of HIV” (Sister Maria-Anna, Teacher, Rural Primary School)
\end{abstract}

Such small-scale, day-to-day interventions are doubtless significant to many thousands of children. However, education systems more widely are seldom organised around an ethic of care, and across Africa, "Generally speaking ... it has been left to individual teachers to assist orphans and other needy children as they see fit" (Bennell et al 2002:62). If schools are to assist more adequately in securing the daily reproduction needs of Lesotho, education needs to be seen in terms other than producing a workforce for the future.

\title{
Acknowledgements
}

Research for this paper was funded by an RGS-IBG Small Research Grant. I am grateful to all of those who gave up their time to be interviewed.

\section{References}

Aitken S, Lopez Estrada S, Jennings J and Aguirre L M (2006) Reproducing life and labor: global processes and working children in Tijuana, Mexico. Childhood I3(3):365-387

Aitken S C (200I) Global crises of childhood: rights, justice and the unchildlike child. Area $33(2): 119-127$

Althusser L (1972) Ideology and ideological state apparatuses. In Cosin B R (ed) Education: structure and society Harmondsworth: Penguin

Ansell N (2002) 'Of course we must be equal, but ...": imagining gendered futures in two rural southern African secondary schools. Geoforum 33(179-194

Ansell N (2002) Secondary education reform in Lesotho and Zimbabwe and the needs of rural girls: pronouncements, policy and practice. Comparative Education 38(I):9I-II2

Ansell $\mathrm{N}$ and van Blerk L (2004) Children's migration as a household/family strategy: coping with AIDS in Malawi and Lesotho. Journal of Southern African Studies 30(3):673-690

Apple MW (1982) Education and power. Boston: Routledge and Kegan Paul 
Barnett T and Whiteside A (2002) AIDS in the Twenty-First Century: Disease and Globalisation.

Basingstoke: Palgrave Macmillan

Bennell P, Hyde K and Swainson N (2002) The Impact of The HIVIAIDS Epidemic on the Education Sector in Sub-Saharan Africa: a Synthesis of the Findings and Recommendations of Three Country Studies. Centre for International Education, University of Sussex Institute of Education Bezuidenhout A and Fakier K (2006) Maria's burden: contract cleaning and the crisis of social reproduction in post-apartheid South Africa. Antipode 38(3):462-485

Boler T and Aggleton P (2005) Life Skills-Based Education for HIV Prevention: a Critical Analysis.

London: Save the Children and ActionAid International

Bosco F J (2007) Hungry children and networks of aid in Argentina: thinking about geographies of responsibility and care. Children's Geographies 5(I-2):55-76

Bourdieu P and Passeron J (1977) Reproduction in Education, Society and Culture. London: Sage Bourdillon M F C (1999) The Next Generation. Wageningen:

Bowles S and Gintis H (1976) Schooling in Capitalist America: Educational Reform and the

Contradictions of Economic Life. London: Routledge and Kegan Paul

Bujra J (2004) AIDS as a crisis in social reproduction. Review of African Political Economy I02(63 I638

Bunge W (1977) The point of reproduction: a second front. Antipode 9(2):60-76

Danziger R (1994) The social impact of HIVIAIDS in developing countries. Social Science and Medicine 39(7):905-917

Demaine J (2003) Social reproduction and education policy. International Studies in Sociology of Education I3(2): $125-140$

Desmond C, Michael K and Gow J (2000) The hidden battle: HIVIAIDS in the household and community. South African Journal of International Affairs 7(2):39-58

Epprecht M 2000 'This Matter of Women is Getting Very Bad': Gender, Development and Politics in Colonial Lesotho University of Natal Press, Pietermaritzburg

Family Health International (200I) Care for Orphans, Children Affected by HIVIAIDS and Other Vulnerable Children: a Strategic Framework. Arlington VA: Family Health International Fine B and Saad-Filho A (2004) Marx's Capital. London: Pluto Press Freire P (1972) Pedagogy of the Oppressed. Harmondsworth: Penguin

Government of Lesotho/UNFPA (2003) Project Document Agreement: POP/FLE in Schools. Maseru, Lesotho: Ministry of Education

Haylett C (2003) Remaking labour imaginaries: social reproduction and the internationalising project of welfare reform. Political Geography 22(765-788 
Human Rights Watch (2005) Letting them fail: government neglect and the right to education for children affected by AIDS. Human Rights Watch I7(I3 (A)): I-57

IATT (2006) Education Sector Global HIV \& AIDS Readiness Survey 2004: Policy Implications for

Education and Development. UNESCO Paris: UNAIDS Inter-Agency Task Team on Education

IATT (2004) Report on the Education Sector Global HIVIAIDS Readiness Survey. IIEP/UNESCO Paris:

UNAIDS Inter-Agency Task Team on Education

James A, Jenks C and Prout A (1998) Theorising Childhood. New York: Teachers College Press

Jennings J, Aitken S, Lopez Estrada S and Fernandez A (2006) Learning and earning: relational scales of children's work. Area 38(3):231-239

Katz C (2004) Growing up Global: Economic Restructuring and Children's Everyday Lives. Minneapolis:

University of Minnesota Press

Katz C (199I) Sow what you know: the struggle for social reproduction in rural Sudan. Annals of the Association of American Geographers 8I(3):488-5I4

Katz C (200I) Vagabond capitalism and the necessity of social reproduction. Antipode 33(4):708727

Kingdom of Lesotho 2004 Poverty Reduction Strategy 2004/5 - 2006/7 Maseru

Lee R (2000) Social reproduction. In Johnston R J, Gregory D, Pratt G and Watts M (eds)

Dictionary of Human Geography. Oxford: Blackwell

Lehohla L (2002) HIVIAIDS and education. Mauritius:

Loevinsohn M and Gillespie S (2003) HIVIAIDS, Food Security and Rural Livelihoods: Understanding and Responding. Washington DC: IFPRI

Mahon R (2006) Of scalar hierarchies and welfare redesign: child care in three Canadian cities.

Transactions of the Institute of British Geographers 3I 452-466

Mattingly D J (200I) The home and the world: domestic service and international networks of caring labor. Annals of the Association of American Geographers 9I (2):370-386

Mayo P (1995) Critical literacy and emancipatory politics: the work of Paulo Freire. International Journal of Educational Development I5(4):363-379

McDowell L (2005) Love, money, and gender divisions of labour: some critical reflections on welfare-to-work policies in the UK. Journal of Economic Geography 5(3):365-379

McDowell L, Ray K, Perrons D, Fagan C and Ward K (2005) Women's paid work and moral economies of care. Social and Cultural Geography 6(2):219-236

Ministry of Education and Training (2004) National Report on the Development of Education, Kingdom of Lesotho. International Conference on Education, Geneva: 
Mitchell K (2003) Educating the national citizen in neoliberal times: from the multicultural self to the strategic cosmopolitan. Transactions of the Institute of British Geographers 28(4):387-403

Mitchell K, Marston S A and Katz C (2003) Introduction: Life's work: an introduction, review and critique. Antipode 4I5-442

Munthali A C and Ali S (2000) Adaptive Strategies and Coping Mechanisms: the Effect of HIVIAIDS on the Informal Social Security System in Malawi. Lilongwe: Government of Malawi, National Economic Council

Murray C (198I) Families Divided: the Impact of Migrant Labour in Lesotho. Cambridge: Cambridge University Press

Pavlovskaya M (2004) Other transitions: multiple economies of Moscow households in the 1990s. Annals of the Association of American Geographers 94(2):329-35 I

Perrons D (2000) Flexible working and equal opportunities in the United Kingdom: a case study from retail. Environment and Planning A 32(10):1719-1734

Piot P (200I) Education in the era of HIV/AIDS: meeting its challenges. In Education International (ed) Dossier: Education in the era of HIVIAIDS

Qvortrup J (2005) Varieties of childhood. In Qvortrup J (ed) Studies in Modern Childhood: Society, Agency, Culture Palgrave Macmillan

Qvortrup J, Bardy M, Sgritta G and Wintersberger H (1994) Childhood Matters: Social Theory,

Practice and Politics. Aldershot: Avebury Press

Republic of Kenya (2004) Education Sector Policy on HIV and AIDS. Nairobi, Kenya:

Republic of Zambia (2003) HIVIAIDS Guidelines for Educators. Zambia: Ministry of Education

Rispel L, Letlape L and Metcalf C (2006) Education Sector Responses to HIV and AIDS: Learning from Good Practices in Africa. London: Commonwealth Secretariat

Robson E (2004) Children at work in rural northern Nigeria: patterns of age, space and gender. Journal of Rural Studies 20(2):193-210

Robson E (2004) Hidden child workers: young carers in Zimbabwe. Antipode 36(2):227-248

Robson E (2000) Invisible carers: young people in Zimbabwe's home-based healthcare. Area 32(I):59-70

Robson E and Ansell N (2000) Young carers in southern Africa: exploring stories from Zimbabwean secondary school students. In Valentine G (ed) Children's Geographies: Playing, Living, Learning. London: Routledge

Robson E, Ansell N, Huber U S, Gould W T S and Van Blerk L (2006) Young caregivers in the context of the HIVIAIDS pandemic in sub-Saharan Africa. Population, Space and Place |2(2):93-III 
Ruddick S (2007) At the horizons of the subject: neo-liberalism, neo-conservatism and the rights of the child. Part Two: Parent, caregiver, state. Gender, Place and Culture 14(6):627-640

Ruddick S (2003) The politics of aging: globalization and the restructuring of youth and childhood. Antipode 35(2):334-362

SADC (2002) National and sector HIVIAIDS policies in the member states of the Southern African Development Community. Prepared for the SADC/HSU by the POLICY Project

Smith N (2002) New globalism, new urbanism: gentrification as global urban strategy. Antipode 34(3):427-450

UNAIDS (2006) Report on the global AIDS epidemic. Geneva: UNAIDS

UNAIDS (2004) Report on the global HIVIAIDS epidemic. Geneva: UNAIDS

UNAIDS/UNICEF/USAID (2004) Children on the Brink: a Joint Report of New Orphan Estimates and a Framework for Action. New York:

UNESCO (2004) The Untapped Potential of School Directors in Strengthening School-based Responses to HIVIAIDS. Bangkok:

United Nations (2007) UN Millennium Development Goals.

Ward K, Fagan C, McDowell L, Perrons D and Ray K (2007) Living and working in urban working class communities. Geoforum 38(2):312-325

Waters J L (2006) Emergent geographies of international education and social exclusion. Antipode 38(5): $1046-1068$

Waters J L (2002) Flexible families? "Astronaut" households and the experiences of lone mothers in Vancouver, British Columbia. Social and Cultural Geography 3(2): I I7-I 34

Waters J L (2006) Geographies of cultural capital: education, international migration and family strategies between Hong Kong and Canada. Transactions of the Institute of British Geographers $3 \mid(2): 179-192$

World Bank (1997) Confronting AIDS: Public Priorities in a Global Epidemic. New York: Oxford University Press

\footnotetext{
'The term Basotho (singular Mosotho) refers to the people of Lesotho.

ii Mining companies today are willing to invest in the health of their HIV-positive miners by supplying antiretroviral drugs.

iii Respondents occupied a range of managerial posts including the Principal Secretary of the Ministry of Education and Training, the United Nations Resident Representative in Lesotho, programme officers in NGOs and advisers in government agencies.

iv Neither of these figures gives a very precise picture of school attendance. The Gross Enrolment Rate of $128 \%$ includes a high number of over- and under-age students, while the Net Enrolment Rate of $85 \%$ probably underestimates the proportion of children receiving schooling, as many do not register for school until some time after their $6^{\text {th }}$ birthday, especially in rural areas where travel to school is difficult for very young children. Both figures reflect registration rather than actual attendance which may be considerably lower.
} 